Original Research Article

\title{
Comparison of safety and efficacy of dextromethorphan and levocloperastine in treatment of dry cough: a randomized open label phase IV clinical trial
}

\author{
Arijit Ghosh*
}

Department of Pharmacology, Malda Medical College, Malda, West Bengal, India

Received: 29 July 2019

Revised: 06 September 2019

Accepted: 09 September 2019

\section{*Correspondence to:}

Dr. Arijit Ghosh,

Email: drarijitghosh@gmail.com

Copyright: (C) the author(s), publisher and licensee Medip Academy. This is an openaccess article distributed under the terms of the Creative Commons Attribution NonCommercial License, which permits unrestricted noncommercial use, distribution, and reproduction in any medium, provided the original work is properly cited.

\begin{abstract}
Background: To compare safety and efficacy of dextromethorphan and levocloperastine in treatment of dry cough.

Methods: Patients fulfilling the selection criteria were randomized into two groups. Patients in group A were administered dextromethorphan cough lozenges $(5 \mathrm{mg})$ thrice daily for 7 days. Patients in group B were administered syrup levocloperastine $(20 \mathrm{mg} / 5 \mathrm{ml}) 5 \mathrm{ml}$ thrice daily for 7 days. Severity and frequency of cough, and Leicester Cough Questionnaire (LCQ) score were assessed at the end of day 7.

Results: Levocloperastine significantly decreased $(\mathrm{p}<0.5)$ severity and frequency of cough compared to dextromethorphan at day 7. Levocloperastine also significantly increased LCQ score compared to dextromethorphan at day 7 . Conclusions: Levocloperastine is significantly more effective compared to dextromethorphan in treatment of dry cough.
\end{abstract}

Keywords: Levocloperastine, Dry cough, Dextromethorphan

\section{INTRODUCTION}

Persistent cough is one of the most common reasons for patients to seek medical advice. Cough is a protective reflex and an innate defence mechanism of respiratory tract. Cough enables us to clear mucous, noxcious substances etc from larynx, trachea and larger bronchi. ${ }^{1}$ Cough is characterized by an initial, short inspiratory phase, followed by closure of the glottis and rapid expiration with violent expulsion of air. ${ }^{2}$ Dry cough is caused due to sensitization of cough receptors. Increased levels of inflammatory mediators (bradykinin, histamine etc.), chemical irritants or pollutants lead to sensitization of cough receptors.
Codeine and dextromethorphan are two most widely used centrally acting antitussive drugs in patients with dry cough. But both drugs are associated with adverse drug reactions like sedation, nausea etc. that promoted the need for more effective and better tolerated antitussive drug. ${ }^{3}$ Levocloperastine is a levorotatory isomer of DLcloperastine. It is described to have antitussive effects both centrally on bulbar cough centre and peripherally on the cough receptors in the tracheobronchial tree. ${ }^{4}$ Satish et al reported that levocloperastine is safe and effective in management of dry cough in Indian patients. It decreases severity scores, frequency of cough and sleep disruption. ${ }^{3}$ Few studies have also compared the safety and efficacy of levocloperastine with codeine. ${ }^{4}$ But none of trials so far have compared the efficacy and safety of levocloperastine with dextromethorphan. So objective of 
our study is to compare safety and efficacy of dextrometorphan and levocloperastine in treatment of dry cough.

\section{METHODS}

This prospective, randomized, open-label, parallel group phase IV clinical trial was approved by the Institutional Ethics Committee and conducted according to the National Ethical Guidelines for Biomedical and Health Research involving Human Participants, 2017 of ICMR and the Declaration of Helsinki. The study was carried out between May and July 2019. Patients were recruited in the general outpatient department of a tertiary care teaching hospital of a district headquarter. The study was registered under Clinical Trials Registry-India (Registration Number-CTRI/2019/04/018787).

Difference of means to be detected was set at $10 \%$. Considering the true mean difference between two treatment groups as zero and the expected standard deviation of $10 \%$ in the study population, $80 \%$ power and $\alpha=0.05$, the number of subjects required in each treatment group was 17 . Considering a $10 \%$ dropout rate, this translated to target recruitment of 19 patients in each group. The sample size was calculated using primer of biostatistics software (version 5.0) (Appleton and Lange, New York, USA.)

Patients between 18 and 60 years of age of either sex with acute dry cough were included in the study. Patients with age out of range, using any anti-cough medications, having co-morbid respiratory, cardiovascular and psychiatric conditions or co-administration of drugs that are likely to interact with levocloperastine or dextromethorphan was excluded from the study.

Patients fulfilling the selection criteria were randomized to one of the two parallel arms of the study. Randomization was done using a computerized random number list with recruitment in each arm in a 1:1 ratio. Patients in group A were administered dextromethorphan cough lozenges (5 mg) (Glenmark Pharmaceuticals, Mumbai, India) thrice daily for 7 days. Patients in group B were administered syrup levocloperastine $(20 \mathrm{mg} / 5 \mathrm{ml})$ (Lupin Ltd,Mumbai, India) $5 \mathrm{ml}$ thrice daily for 7 days. For each enrolled subject the total duration of the study was one week. The study consisted of two visits baseline visit on day 0 and end of treatment visit at day 7 . Trial drugs were dispensed once at baseline visit for 7 days. Patients were also followed up over telephone on day 3 and asked to report for worsening symptoms.

The primary efficacy parameter was change in severity of cough. It was assessed on $100 \mathrm{~mm}$ visual analogue scale (VAS) where score 0 indicates no cough and score 100 indicates worst cough ever. ${ }^{3}$ The frequency of cough since last $24 \mathrm{~h}$ was recorded on a 7-point Likert scale. The score of 0 indicated "not at all", 1 "occasional", 2 "a little", 3 "somewhat", 4 "a lot", 5 "very much", and 6 "constant". 3 The quality of life (QoL) was be assessed using 19-item patient-reported Leicester Cough Questionnaire (LCQ). ${ }^{5}$ The LCQ comprises of three health domains: physical, psychological and social. Each item assesses symptoms or the impact of symptoms on a 7-point Likert scale. The domain score ranges from 1 to 7 and the total score ranges from 3 to 21. The total score was calculated by adding the domain scores together. The higher score indicated better QoL of a patient. ${ }^{3,6}$

Patients with worsening clinical conditions or severity and frequency of cough were withdrawn prematurely from the study. All patients were advised to stop smoking and consumption of alcohol during the study period. Patients were monitored continuously throughout the study for any adverse event (AE). Causality analysis of $\mathrm{AE}$ was done as per the World Health OrganizationUppsala Monitoring Centre (WHO-UMC) criteria. $^{7}$

\section{Statistical analysis}

Data were analyzed as per modified intention to treat (ITT) basis. Subjects reporting for at least one post baseline follow-up visit over telephone were analyzed. All patients who were randomized were considered for safety analysis. Wilcoxon signed rank test used for intragroup comparison and Mann-Whitney $U$ test used for inter-group comparison. Categorical data in baseline demographic profile (gender) were analyzed by chisquare test. $\mathrm{P}$ value $<0.05$ was considered to be statistically significant.

\section{RESULTS}

Initially 40 patients were screened for the clinical trial. 19 patients were included in each group. In group A patients received dextromethorphan (Glenmark Pharmaceuticals, Mumbai, India). Patients of group B patients received levocloperastine (Lupin Ltd, Mumbai, India). Out of these 38 patients, 35 patients completed the study. Three patients were lost during follow up (Figure 1). The mean age of the patients was 29.2 and 31.5 years in Groups A and $\mathrm{B}$, respectively.

There was no statistically significant difference in the baseline severity of cough, frequency of cough and LCQ score. Severity and frequency of cough decreased significantly in both groups A and B on day 7 from their respective baseline values $(\mathrm{p}<0.5)$.

Severities of cough in group A were 69.7 \pm 3.2 and $12.8 \pm 1.9$ at days 0 and 7 respectively. Severities of cough in group B at days 0 and 7 were $69.6 \pm 2.6$ and $6.2 \pm 1.3$ respectively. $p<0.05$ was day 7 versus day 0 in groups $A$ and B. At day $7 \mathrm{p}<0.05$ was group B versus group A (Table 1).

Frequencies of cough in group A were $3.5 \pm 0.5$ and $1.2 \pm 0.4$ at days 0 and 7 respectively. Frequencies of cough in group $\mathrm{B}$ at days 0 and 7 were $3.6 \pm 0.5$ and 
$0.8 \pm 0.6$ respectively. $\mathrm{p}<0.05$ was day 7 versus day 0 in groups A and B. At day $7 \mathrm{p}<0.05$ was group B versus group A (Table 2).

LCQ score increased significantly in both groups A and $B$ on day 7 from their respective baseline values $(p<0.5)$.
LCQ scores of cough in group A were $6.7 \pm 0.6$ and $10.7 \pm 0.7$ at days 0 and 7 respectively. LCQ scores of cough in group $\mathrm{B}$ at days 0 and 7 were $6.6 \pm 0.7$ and $12.3 \pm 0.9$ respectively. $\mathrm{P}<0.05$ was day 7 versus day 0 in groups A and B. At day $7 \mathrm{p}<0.05$ was group B versus group A (Table 3).

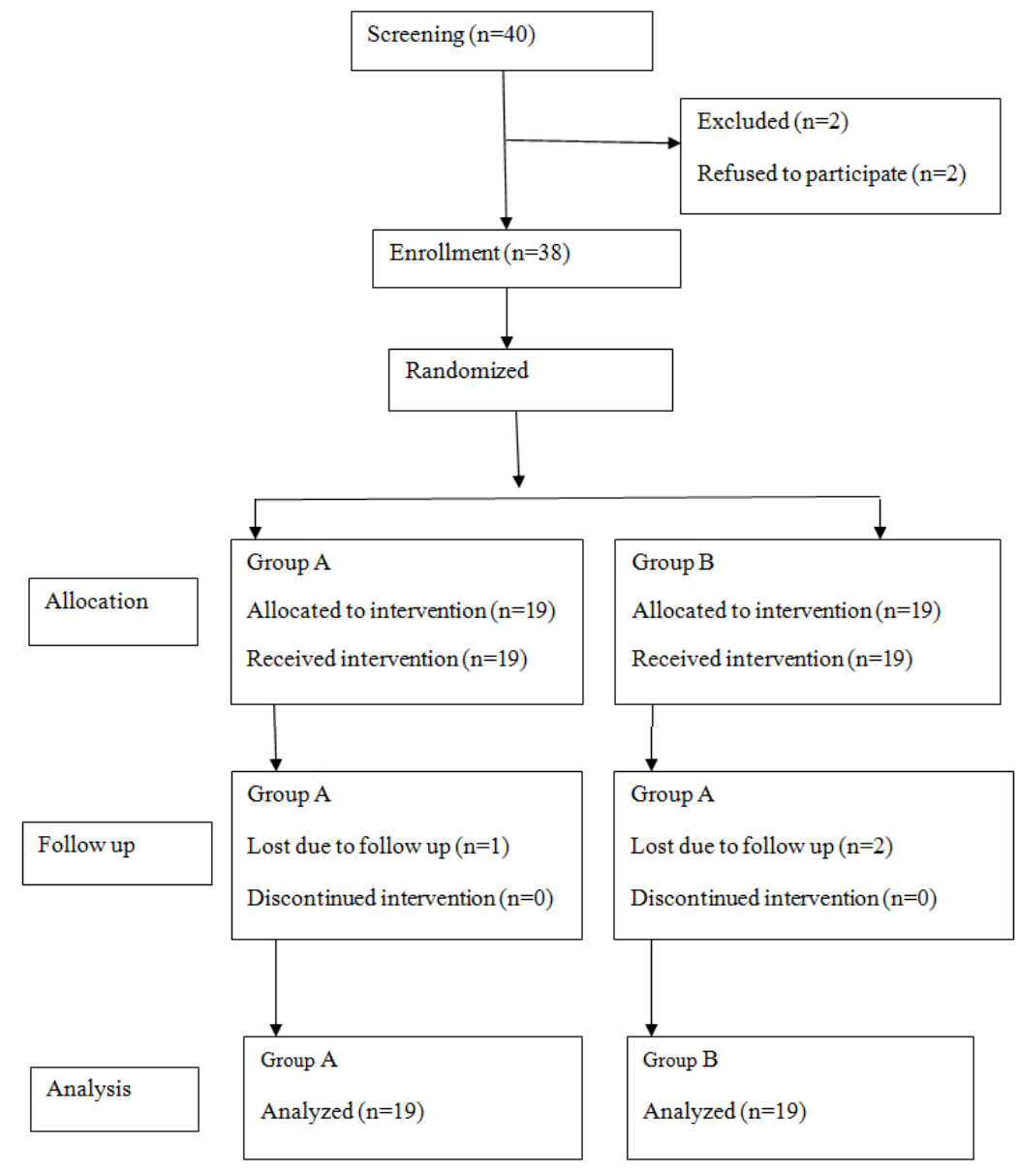

Figure 1: The CONSORT 2010 flow diagram showing allocation, follow-up, and analysis subjects in groups $\mathbf{A}$ and $\mathbf{B}$.

Table 1: Changes in severity of cough in groups $\mathbf{A}$ and $\mathbf{B}$.

\begin{tabular}{|llll|}
\hline $\begin{array}{l}\text { Severity of } \\
\text { cough }\end{array}$ & Group A & Group B & P value \\
\hline $\begin{array}{l}\text { Day 0 } \\
\text { (mean } \pm \text { SD) }\end{array}$ & $69.7 \pm 3.2$ & $69.6 \pm 2.6$ & 0.9 \\
\hline $\begin{array}{l}\text { Day 7 } \\
\text { (mean } \pm \text { SD) }\end{array}$ & $12.8 \pm 1.9$ & $6.2 \pm 1.3$ & $<0.05$ \\
\hline P value & $<0.05$ & $<0.05$ & \\
\hline
\end{tabular}

Inter group analysis show at day 7 levocloperastine (group B) significantly decreased $(\mathrm{p}<0.5)$ severity and frequency of cough compared to dextromethorphan (group A). Levocloperastine also significantly increased LCQ score compared to dextromethorphan at day 7.

Safety analysis was carried out as per ITT analysis. All patients who were randomized were considered for safety analysis. Total five patients reported AEs. All five patients were from group A. AEs were sedation and drowsiness noted during initiation of therapy. These AEs were mild to moderate in nature. Causality analysis showed that they were in the "possible" category. Causality analysis was done as per the WHO-UMC criteria.

Table 2: Changes in frequency of cough in groups $\mathbf{A}$ and $\mathbf{B}$.

\begin{tabular}{|llll|}
\hline $\begin{array}{l}\text { Frequency of } \\
\text { cough }\end{array}$ & Group A & Group B & P value \\
\hline $\begin{array}{l}\text { Day 0 } \\
\text { (mean } \pm \text { SD) }\end{array}$ & $3.5 \pm 0.5$ & $3.6 \pm 0.5$ & 1 \\
\hline $\begin{array}{l}\text { Day 7 } \\
\text { (mean } \pm \text { SD) }\end{array}$ & $1.2 \pm 0.4$ & $0.8 \pm 0.6$ & $<0.05$ \\
\hline P value & $<0.05$ & $<0.05$ & \\
\hline
\end{tabular}


Table 3: Changes in LCQ score of cough in groups $\mathbf{A}$ and $\mathbf{B}$.

\begin{tabular}{|lll|l|}
\hline LCQ score & Group A & Group B & P value \\
\hline $\begin{array}{l}\text { Day 0 } \\
\text { (mean } \pm \text { SD) }\end{array}$ & $6.7 \pm 0.6$ & $6.6 \pm 0.7$ & 0.9 \\
\hline $\begin{array}{l}\text { Day 7 } \\
\text { (mean } \pm \text { SD) }\end{array}$ & $10.7 \pm 0.7$ & $12.3 \pm 0.9$ & $<0.05$ \\
\hline P value & $<0.05$ & $<0.05$ & \\
\hline
\end{tabular}

\section{DISCUSSION}

Cough has been identified as the sixth commonest reason to visit outpatient department of hospital. ${ }^{8}$ Dry cough is a common problem encountered in clinical practice. Dry cough is often annoying to patients. It may lead to disruption of sleep due to night-time awakening and affect quality of life. ${ }^{3,9}$ So adequate management of dry cough with an antitussive agent is a necessary.

Dextromethorphan and codeine are the most preferred antitussive agent by the physician. Dextromethorphan was first reported in 1953 for treatment of cough devoid of adverse effects of codeine. ${ }^{4,10}$ However both drugs have been reported to cause sedation and drowsiness. On the other hand levocloperastine is a novel antitussive drug with a pharmacological profile distinct from that of racemic DL-cloperastine.

Data from our study show that levocloperastine significantly decreased severity and frequency of cough compared to dextromethorphan at the end of day 7. Our study further reveals that levocloperastine significantly increased LCQ score compared to dextromethorphan at day 7. Alprandi et al described six open trials on levocloperastine. ${ }^{11}$ These trials evaluated efficacy and safety of levocloperastine in various respiratory diseases like bronchitis, asthma, COPD and pneumonia. In all these trials levocloperastine significantly decreased severity and frequency of cough. Levocloperastine has also been found to be effective in children. In adults it showed to decrease ACE inhibitors induced cough. Levocloperastine is also reported to have comparable efficacy, rapid onset of action and no central adverse effects compared to codeine. ${ }^{4}$ Thus levocloperastine has been proved to be an effective antitussive agent in patients with all age group for treatment of cough. Satish et al reported that levocloperastine is safe and effective in management of dry cough in Indian patients. ${ }^{3}$ It decreased severity scores, frequency of cough, sleep disruption and increased LCQ scores. Data from our study are also in agreement with these studies.

\section{CONCLUSION}

The result of this randomized, open lable phase IV clinical trial shows that levocloperastine was significantly more effective compared to dextromethorphan. Levocloperastine is also proved to be safe.

Funding: No funding sources

Conflict of interest: None declared

Ethical approval: The study was approved by the Institutional Ethics Committee

\section{REFERENCES}

1. Morice AH, Jakes AD, Faruqi S, Birring SS, McGarvey L, Canning B, et al. A worldwide survey of chronic cough: amanifestation of enhanced somatosensory response. Eur Respir J. 2014;44:114955.

2. Scotti L, Borzani M. Cloperastine fendizoate in the treatment of coughproducing diseases in pediatrics. Minerva Pediatr. 1988;40:283-6.

3. Satish K, Sholapuri D, Niranjane V, Garg S. Efficacy and safety of levocloperastine in the treatment of dry cough: a prospective observational Study. J Assoc Phys India. 2018;66:71-5.

4. Dicpinigaitis PV, Morice AH, Birring SS, McGarvey L, Smith JA, Canning BJ, et al. Antitussive DrugsPast, Present, and Future. Pharmacol Rev. 2014;66:468-512.

5. Yousaf N, Lee KK, Jayaraman B, Pavord ID, Birring SS. The assessment of quality of life in acute cough with the Leicester Cough Questionnaire (LCQ-acute). Cough. 2011;7:4-6.

6. Juniper EF, Guyatt GH, Willan A, Griffith LE. Determining a minimal important change in a disease-specific Quality of Life Questionnaire. J Clin Epidemiol. 1994;47:81-7.

7. Edwards IR, Aronson JK. Adverse drug reactions: Definitions, diagnosis, and management. Lancet. 2000;356:1255-9.

8. Pore R, Biswas S, Das S. Prevailing Practices for the Management of Dry Cough in India: A Questionnaire Based Survey. J Assoc Phys India. 2016;64:48-54.

9. Morice AH, McGarvey L, Pavord I. Recommendations for the management of cough in adults. Thorax. 2006;61:i1-24.

10. Cass LJ, Frederik WS, Andosca JB. Quantitative comparison of dextromethorphan hydrobromide and codeine. Am J Med Sci. 1954;227:291-6.

11. Aliprandi P, Castelli C, Bernorio S, Dell'Abate E, Carrara M. Levocloperastine in the treatment of chronic non-productive cough: comparative efficacy versus standard antitussive agents. Drugs Exp Clin Res. 2004;30:133-41.

Cite this article as: Ghosh A. Comparison of safety and efficacy of dextromethorphan and levocloperastine in treatment of dry cough: a randomized open label phase IV clinical trial. Int J Basic Clin Pharmacol 2019;8:2284-7. 